\title{
Kinetics and Mechanism of Mineral Respiration: How Iron Hemes Synchronize Electron Transfer Rates
}

\author{
Valentin Chabert, Lucille Babel, Michael P. Füeg, Maksym Karamash, Edwin S. Madivoli, \\ Nelly Herault, Joana M. Dantas, Carlos A. Salgueiro, Bernd Giese, * and Katharina M.
}

Fromm*

\begin{abstract}
Anaerobic microorganisms of the Geobacter genus are effective electron sources for the synthesis of nanoparticles, for bioremediation of polluted water, and for the production of electricity in fuel cells. In multistep reactions, electrons are transferred via iron/heme cofactors of c-type cytochromes from the inner cell membrane to extracellular metal ions, which are bound to outer membrane cytochromes. We measured electron production and electron flux rates to $5 \times 10^{5}$ es $^{-1}$ per G. sulfurreducens. Remarkably, these rates are independent of the oxidants, and follow zero order kinetics. It turned out that the microorganisms regulate electron flux rates by increasing their $\mathrm{Fe}^{2+} / \mathrm{Fe}^{3+}$ ratios in the multiheme cytochromes whenever the activity of the extracellular metal oxidants is diminished. By this mechanism the respiration remains constant even when oxidizing conditions are changing. This homeostasis is a vital condition for living systems, and makes G. sulfurreducens a versatile electron source.
\end{abstract}

$S_{\text {ome anaerobic microorganisms are able to use extracellu- }}$ lar metal salts as terminal oxidants in their respiratory pathways (mineral respiration). ${ }^{[1]}$ Important examples are bacteria of the Geobacter genus, ${ }^{[2]}$ which turned out to be effective electron sources for the synthesis of nanoparticles, ${ }^{[3]}$ for bioremediation of toxic and radioactive metals, ${ }^{[4]}$ and for the current production in microbial fuel cells. ${ }^{[5]}$ The respiratory pathways are based on electron transfer (ET) from the inside of the cells to the exterior. ET reactions can be mediated by proteins of bacterial filaments or by $c$-type cytochromes. ${ }^{[1,6,7]}$ We studied ET processes, where $c$-type

[*] Dr. V. Chabert, Dr. L. Babel, M. Karamash, E. S. Madivoli,

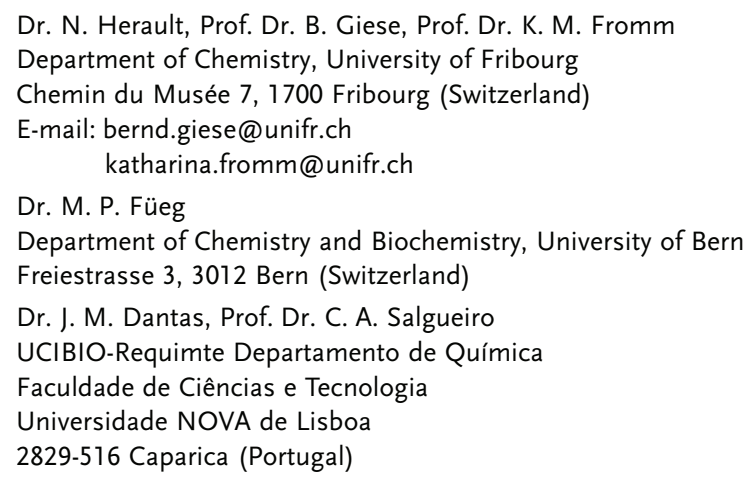

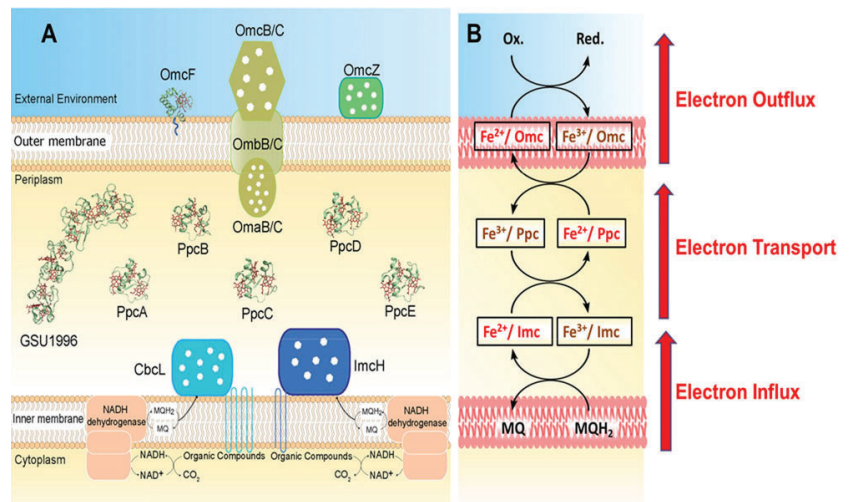

Figure 1. Outline of the inner and outer cell membrane of Geobacter sulfurreducens. A) Multiheme $c$-type cytochromes that are involved in anaerobic (mineral) respiration. Electrons originating from the oxidation of organic compounds are transferred to a menaquinone pool via an NADH hydrogenase located in the inner membrane. Depending on the redox potential of the final electron acceptor, the electrons are transferred to one of two pathways: the CbcL-dependent pathway, which operates when the final oxidants are at or below redox potentials of $-100 \mathrm{mV}$ vs. NHE, or the ImcH pathway, which is used when the final oxidants are above these redox potential values. B) During mineral respiration, several ET steps between the iron/hemes of the multiheme cytochromes transport electrons through the periplasm and the outer membrane to the extracellular oxidant.

cytochromes are the electron carriers (Figure 1). The respiratory chain starts at the inner cell membrane (electron influx) by enzymatic reduction of the $\mathrm{Fe}^{3+} /$ heme cofactors of inner membrane cytochromes (Imc). During electron transport through the periplasm, several ET steps occur within and between the periplasmic multiheme cytochromes (Ppc). Finally, $\mathrm{Fe}^{3+} /$ hemes of the outer membrane cytochromes (Omc) accept these electrons, and reduce the extracellular metal ions (electron outflux).

We have measured the electron production and flux through the cell by in vivo experiments with Geobacter sulfurreducens using $\mathrm{AgNO}_{3}, \mathrm{Na}_{2} \mathrm{CrO}_{4}$, and $\mathrm{AgCl}$ as oxidants (Scheme 1). It turned out that each microorganism produces $5 \times 10^{5}$ electrons per second, and that the electron flux rate is nearly independent of oxidation potentials, aggregation states, charges and concentrations of the extracellular metal salts. This surprising behavior is accomplished by the bacteria, which are able to vary the $\mathrm{Fe}^{2+} / \mathrm{Fe}^{3+}$ ratios in the hemes of the cytochromes, allowing to synchronize the electron outflux rates with the constant electron influx rate. 


\begin{tabular}{|c|c|c|c|}
\hline \multirow{2}{*}{$\begin{array}{l}\text { Electron Outflux } \\
\text { Outer Membrane }\end{array}$} & \multirow{2}{*}{$\mathrm{Fe}^{2+} / \mathrm{Omc}$} & chemical redox reaction & \multirow{2}{*}{$\mathrm{Fe}^{3+} / \mathrm{Omc}$} \\
\hline & & metal salt & \\
\hline \multirow{2}{*}{$\begin{array}{l}\text { Electron Influx } \\
\text { Inner Membrane }\end{array}$} & \multirow{2}{*}{$\mathrm{Fe}^{3+} / \mathrm{Imc}$} & enzymatic redox reaction & \multirow{2}{*}{$\mathrm{Fe}^{2+} / \mathrm{Imc}$} \\
\hline & & Geobacter sulfurreducens & \\
\hline
\end{tabular}

Scheme 1. Chemical oxidation of $\mathrm{Fe}^{2+} /$ hemes by extracellular metal ions (electron outflux), and enzymatic reduction of the $\mathrm{Fe}^{3+} /$ hemes at the inner membrane (electron influx). By measuring the changes in the concentrations of the $\mathrm{Fe}^{2+} /$ hemes and the oxidizing metal ions, the ET rates were determined.

First experiments were performed with $\mathrm{AgNO}_{3}$, which was reduced by G. sulfurreducens to $\mathrm{Ag}$ nanoparticles (AgNPs). Redox reactions between the oxidant and the $\mathrm{Fe}^{2+} /$ hemes rely on complexation of $\mathrm{Ag}^{+}$ions by the amino acids of Omc proteins. High complexation constants prevent the migration of $\mathrm{Ag}^{+}$ions into the cell, and thus protect the bacteria against the toxicity of $\mathrm{Ag}^{+}$ions. To verify $\mathrm{Ag}^{+}$ complexation, NMR titration experiments were carried out with OmcF, the only Omc of G. sulfurreducens whose structure was determined in NMR studies. ${ }^{[8]}$ In the $11 \mathrm{kDa}$ OmcF a methionine, Met 86, and a histidine, His 34, are well oriented for the coordination of a metal ion in a linear fashion (Figure 2 A). Both amino acids are known to bind $\mathrm{Ag}^{+}$ions in peptides. ${ }^{[9]}{ }^{1} \mathrm{H}$ NMR titration of OmcF with silver nitrate in $\mathrm{D}_{2} \mathrm{O}$ confirmed silver complexation by the imidazole group of His 34 as well as by the sulfur atom of Met 86 (Figure S1).

This titration furthermore indicated the formation of a $3: 1$ $\mathrm{Ag}^{+} / \mathrm{OmcF}$ complex (Figure 2B), implying other coordinating residues whose proton signals could not be followed, likely because of the neighboring paramagnetic iron/heme entity. In order to determine the binding constant, we added imidazole- $\mathrm{d}_{4}$ as competing ligand, whose affinity constant to $\mathrm{Ag}^{+}$ions is known. ${ }^{[10]}$ This created two sets of protein signals (Figures 2C and Figure S2), which were due to a partial exchange of the axial His39-heme ligand by the added imidazole- $\mathrm{d}_{4}$. This type of exchange had already been observed in other iron/heme systems, ${ }^{[11]}$ and we confirmed this ligand exchange for $\mathrm{OmcF}$ by variation of the imidazole$\mathrm{d}_{4}$ concentration (Figure S3). From the signals of Met 86 and His 34, two of the three $\mathrm{Ag}^{+} / \mathrm{OmcF}$ binding constants were determined to be $\log K_{1,1}=6.1( \pm 0.3)$ and $\log K_{2,1}=6.2( \pm 0.5)$ (Figure S4). The third complexation could not be fitted with a reasonable error. The binding constants correspond to typical values reported for other histidine/silver/methionine complexes. ${ }^{[9,12]}$ Binding between $\mathrm{Ag}^{+}$and two (protein-free) histidine molecules has also a binding constant on the order of $10^{6} .^{[10]}$ The NMR structures of the other outer membrane cytochromes of G. sulfurreducens such as $\mathrm{OmcB}$ and $\mathrm{OmcC}$ are not known. They are large, multiheme cytochromes with a high number of free histidine residues, which should bind $\mathrm{Ag}^{+}$ions also very efficiently. ${ }^{[13]}$

Experiments to determine the ET rates were carried out with 0.6-0.9 pм G. sulfurreducens and $50 \mu \mathrm{M} \mathrm{AgNO}_{3}$ solutions with low $\mathrm{Cl}^{-}$and $\mathrm{Fe}^{2+}$ concentrations (Figure S5). ${ }^{[14]} \mathrm{UV} / \mathrm{Vis}$ spectra exhibited Soret and Q-bands of the iron hemes, as well as scattering contributions of the microorganisms (Figure $3 \mathrm{~A}$ ). As the AgNP concentration was low, the plasmon
A

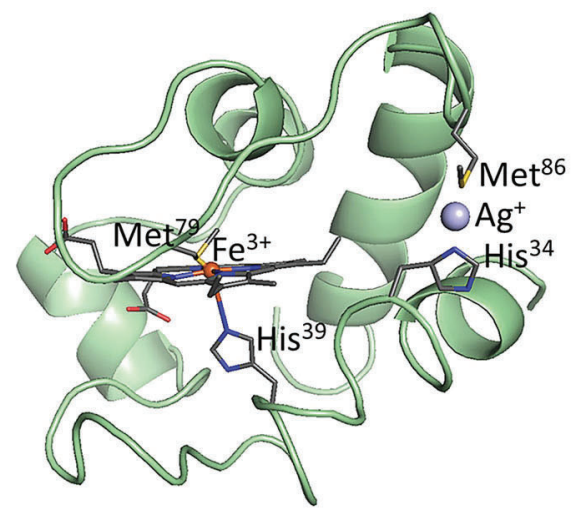

B

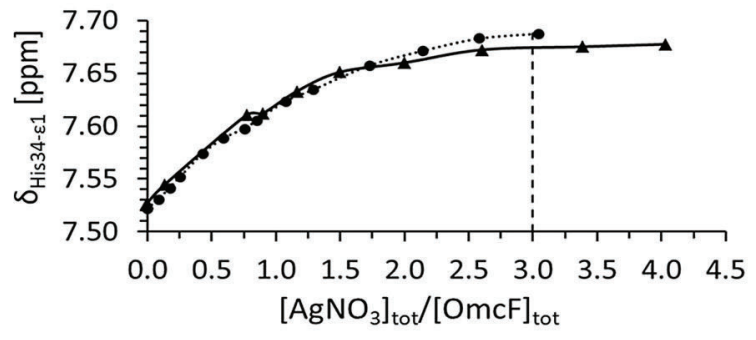

C

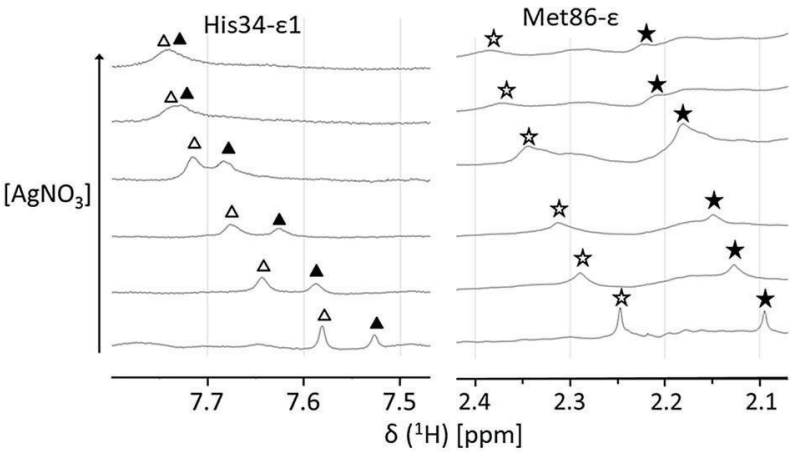

Figure 2. A) Complexation site of one $\mathrm{Ag}^{+}$ion on the outer membrane cytochrome OmcF, containing a Fe${ }^{3+} /$ heme cofactor. The complexation sites of the two other $\mathrm{Ag}^{+}$ions bound by OmcF could not be determined. B) Change in the NMR chemical shift of one aromatic C$\mathrm{H}$ group of $\mathrm{His} 34$ during the addition of $\mathrm{AgNO}_{3}$ on $\mathrm{OmcF}(1.1 \mathrm{~mm}$ : circles, and 0.2 mM: triangles) in HEPES buffer (pD 7.8). A $3: 1 \mathrm{Ag}^{+}$/ OmcF stoichiometry yielded a good fit of the experimental data. C) NMR chemical shifts of one aromatic $\mathrm{C}-\mathrm{H}$ group of $\mathrm{His} 34$ and of the $\mathrm{CH}_{3}$ group of Met 86 (OmcF: $1 \mathrm{~mm}$ ) during addition of $\mathrm{AgNO}_{3}(0-$ $7 \mathrm{mM}$ ). The NMR experiments were carried out in competition with imidazole- $d_{4}$, which duplicated the signals (blank and filled) due to displacement of His 39.

resonance of the AgNPs was weak and overlapped with the iron/heme Soret bands (Figure S6). Therefore, the concentration changes of the $\mathrm{Fe}^{2+}$ /hemes were analyzed by their Qbands (Figure S7). AgNP formation was determined by the increasing scattering of the microorganisms at $610 \mathrm{~nm}$ (Figure $3 \mathrm{C}, \mathrm{D})^{[15]}$ and EDS experiments (Figure S8).

Addition of $\mathrm{AgNO}_{3}$ to G. sulfurreducens oxidized in less than two seconds more than $98 \%$ of the $\mathrm{Fe}^{2+} /$ hemes to $\mathrm{Fe}^{3+}$ / hemes (Figure S9), and the $\mathrm{Fe}^{2+} / \mathrm{Fe}^{3+}$ ratio remained nearly constant for the next 4-5 minutes (Figure $3 \mathrm{~B}$ ). During this time, the light scattering increased in a nearly linear way (Figure 3C), which indicated a constant AgNP formation that was independent of the $\mathrm{Ag}^{+}$concentration. ${ }^{[15]}$ Thus, its rate 

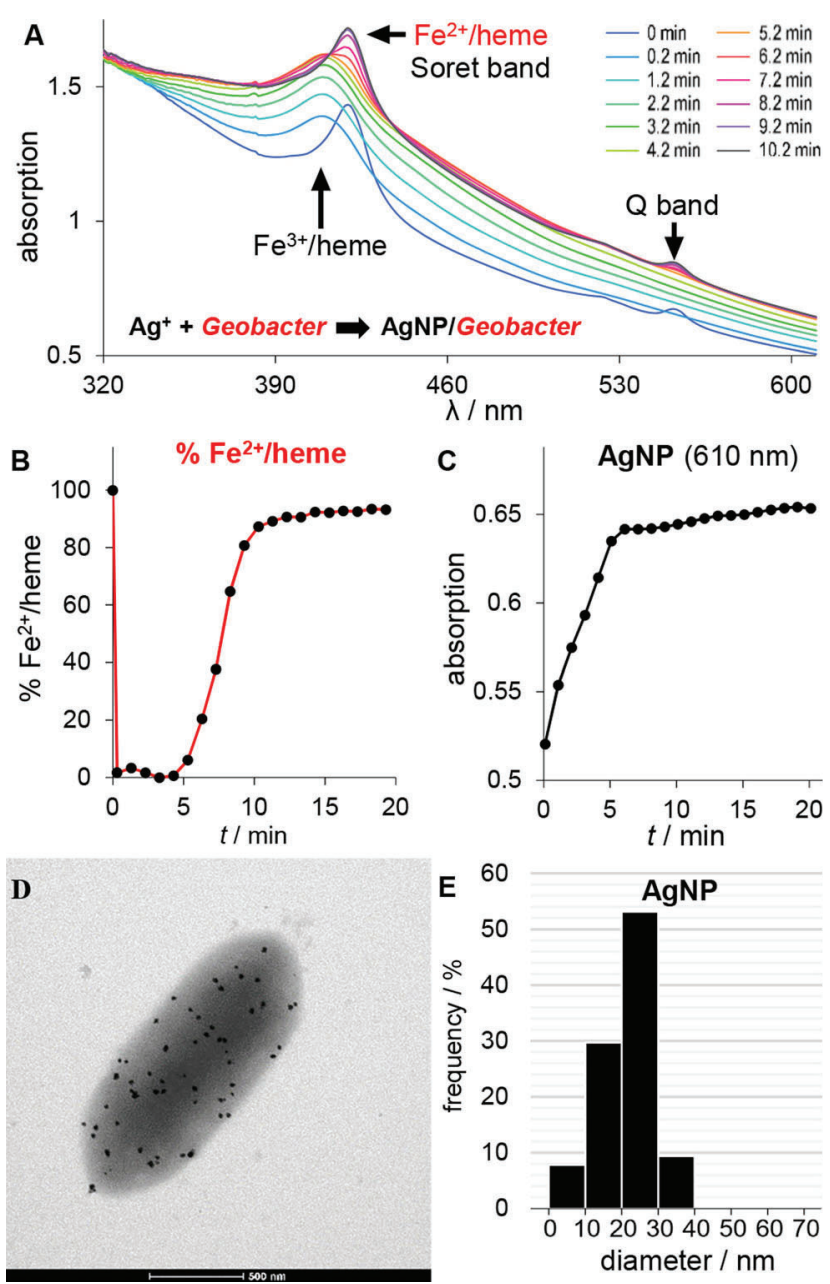

Figure 3. Reduction of $\mathrm{Ag}^{+}$ions $(0.05 \mathrm{~mm})$ by $\mathrm{G}$. sulfurreducens (0.7 pм). A) UV/Vis spectra of the bacterial suspension during $\mathrm{Ag}^{+}$ reduction (indicated times correspond to the measurement start at $610 \mathrm{~nm}$; scan time $=1 \mathrm{~min}$ ). The spectrum at 0 min was registered before $\mathrm{AgNO}_{3}$ addition. B) Time dependence of the $\mathrm{Fe}^{2+}$ /heme concentration, determined from its Q-band (Figure S7). C) Time dependence of the scattering $(610 \mathrm{~nm})$ demonstrating AgNP formation. D) TEM image recorded at the end of the redox reaction showing AgNPs attached to the microorganism. E) Size distribution of AgNPs at the microorganism.

followed zero order kinetics. After consumption of the $\mathrm{Ag}^{+}$ ions, $\mathrm{Fe}^{3+} /$ hemes were reduced back to $\mathrm{Fe}^{2+} /$ hemes (Figure $3 \mathrm{~B})$. The observed zero order kinetics during AgNP formation can be explained by a constant number of reaction sites at which AgNPs grew on the surface of the bacteria (Figure 3D), as well as an excess of $\mathrm{Ag}^{+}$ions (0.7 pM G. sulfurreducens; $0.05 \mathrm{~mm} \mathrm{AgNO}_{3}$ ) at the reaction start. ${ }^{[16]}$ As long as the $\mathrm{Ag}^{+}$ions were in large excess, their addition to the AgNPs $\mathbf{2} \rightarrow \mathbf{3}$ was obviously faster than ET between and through the cytochromes. ${ }^{[17]}$ Thus, the ET steps $\mathbf{3} \rightarrow \mathbf{4}$ and not the $\mathrm{Ag}^{+}$addition to $\mathbf{2}$ were rate determining (Scheme 2). We repeated the measurements more than 10 times with different generations of G. sulfurreducens and calculated an average ET rate of $3.0 \times 10^{5} \mathrm{e} \mathrm{s}^{-1}$ per bacterium with a variation of $\pm 40 \%$ at $30^{\circ} \mathrm{C}$ (Table 1$)$. When the reaction temperature was

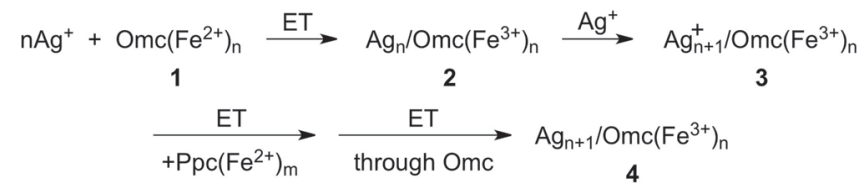

Scheme 2. Formation of AgNPs starts with complexation of $\mathrm{Ag}^{+}$ions to Omc 1 and subsequent oxidation of $\mathrm{Fe}^{2+} /$ hemes to $\mathrm{Fe}^{3+} /$ hemes in 2. The AgNP growth occurs by $\mathrm{Ag}^{+}$addition $(\mathbf{2} \rightarrow \mathbf{3})$, as well as ET steps between and through the $c$-type cytochromes leading to 4 , which continues the AgNP growth.

Table 1: Electron flux rates with different oxidants and different generations of $G$. sulfurreducens.

\begin{tabular}{llll}
\hline Oxidant & $\begin{array}{l}\text { Redox potential } \\
{[\mathrm{V}]^{[\mathrm{a}]}(\mathrm{pH} \mathrm{7})}\end{array}$ & $\begin{array}{l}\text { ET rate } \\
{\left[\mathrm{e} \mathrm{s}^{-1}\right]^{[\mathrm{b}]}}\end{array}$ & $\begin{array}{l}\text { Temperature } \\
{\left[{ }^{\circ} \mathrm{C}\right]}\end{array}$ \\
\hline $\mathrm{AgNO}_{3}$ & 0.80 & $3.0 \times 10^{5}$ & 30 \\
& & $1.5 \times 10^{5}$ & 20 \\
& & $0.8 \times 10^{5}$ & 15 \\
$\mathrm{Na}_{2} \mathrm{CrO}_{4}$ & 0.62 & $5.0 \times 10^{5}$ & 30 \\
$\mathrm{AgCl}$ & 0.21 & $7.5 \times 10^{5}$ & 30 \\
\hline
\end{tabular}

[a] Standard reduction potentials against NHE were used. They were not corrected for the influence of the reaction mixture and the reaction temperature. [b] The variation was $\pm 40 \%$.

decreased to 20 and $15^{\circ} \mathrm{C}$, the electron flux slowed down by a factor of 2.0 and 3.8, respectively.

Interestingly, the initial oxidation of the $\mathrm{Fe}^{2+} /$ hemes of G. sulfurreducens in the resting state by $\mathrm{Ag}^{+}$ions $(\mathbf{1} \rightarrow \mathbf{2})$ was much faster than the electron flux during respiration. It took less than 2 seconds to oxidize nearly all $\mathrm{Fe}^{2+} /$ hemes to $\mathrm{Fe}^{3+}$ / hemes (Figure S9). During this initial phase, about $10 \%$ of the AgNPs were generated. As $\mathrm{Ag}^{+}$ions were in $7 \times 10^{7}$ fold excess to G. sulfurreducens, the reduction of $10 \%$ of the $\mathrm{Ag}^{+}$ ions was caused by $0.7 \times 10^{7} \mathrm{Fe}^{2+} /$ hemes. This number of iron/ hemes per bacterium is in good agreement with direct iron/ heme measurements by Esteve-Núñez et al. ${ }^{[18]}$

A characteristic of the silver ion system is that not the decrease of the oxidants, the $\mathrm{Ag}^{+}$ions, but the increase of the reaction products, the AgNPs, was determined. In order to analyze directly the change of the oxidants by UV/Vis spectroscopy, we used $\mathrm{Na}_{2} \mathrm{CrO}_{4}$ as a reagent (Figure $4 \mathrm{~A}, \mathrm{C}$ ). Another difference in these two oxidants is that $\mathrm{CrO}_{4}{ }^{2-}$ anions instead of $\mathrm{Ag}^{+}$cations were bound by the amino acids of the Omc proteins, and $\mathrm{Cr}^{3+}$ cations instead of $\mathrm{Ag}^{0}$ nanoparticles were formed as reaction products. Several experiments with $0.7-0.9 \mathrm{pm}$ G. sulfurreducens and 0.05 or $0.1 \mathrm{~mm} \mathrm{Na} \mathrm{CrO}_{4}$ solutions at $30^{\circ} \mathrm{C}$ were carried out. ${ }^{[19]}$ Figure $4 \mathrm{C}$ shows that the concentration of the oxidant decreased in a constant way. Thus, also with $\mathrm{Na}_{2} \mathrm{CrO}_{4}$, a concentration change did not influence the redox rate. The reaction was of zero order in chromate, so that its rate could be calculated directly from the decrease in the chromate concentration. An average ET rate of $5.0 \times$ $10^{5} \mathrm{e} \mathrm{s}^{-1}$ per bacterium at $30^{\circ} \mathrm{C}$ was determined (Table 1 ). Interestingly, the $\mathrm{Fe}^{2+}$ /heme concentration increased slightly during the experiment (Figure 4B). This rise could compensate for a slowdown of the redox reaction caused by a decrease of the chromate concentration, or by a change of the redox 

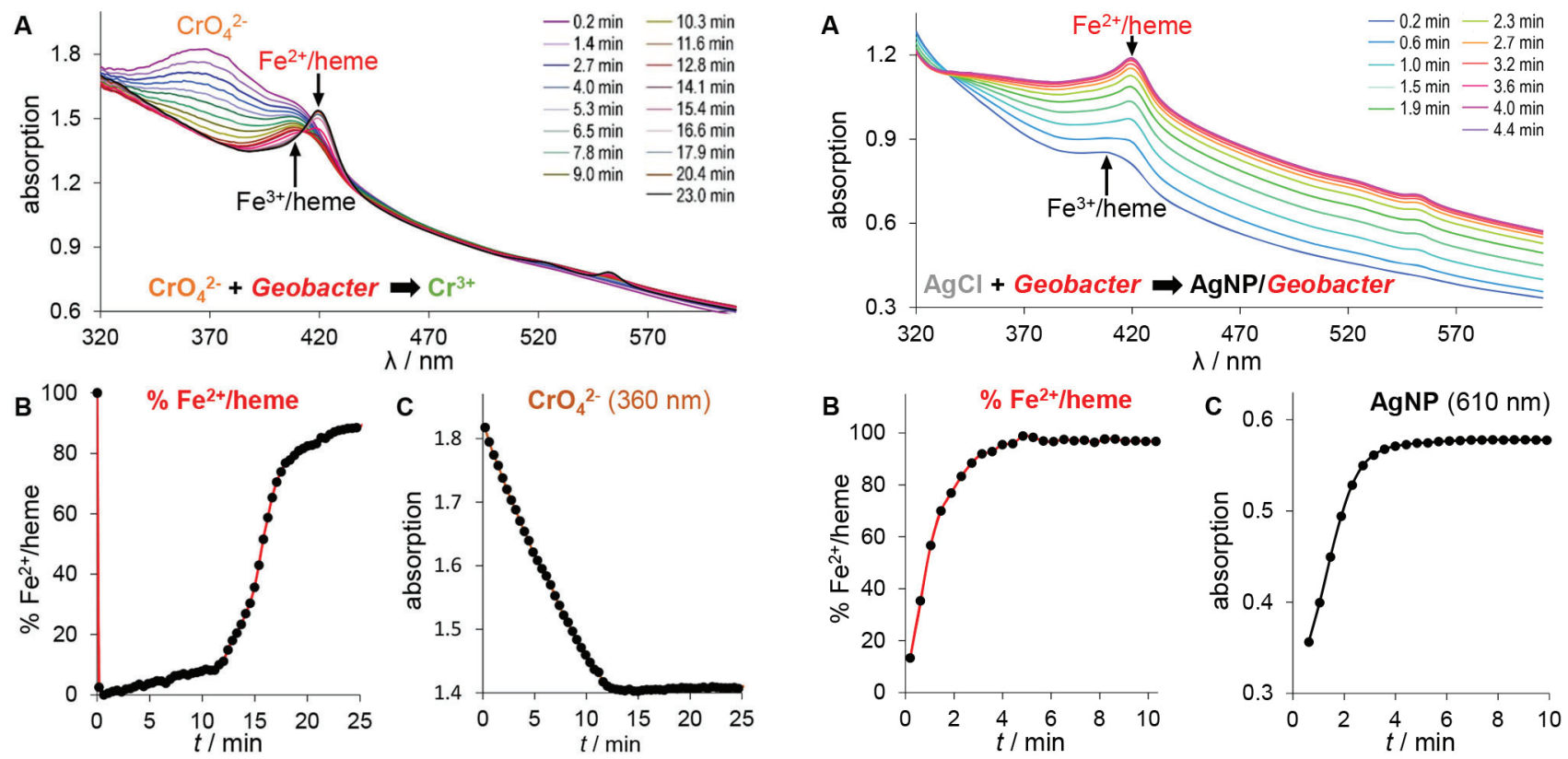

Figure 4. Reduction of $\mathrm{CrO}_{4}{ }^{2-}$ ions $(0.1 \mathrm{mM})$ by G. sulfurreducens (0.8 pM). A) UV/Vis monitoring of the bacterial suspension upon $\mathrm{CrO}_{4}{ }^{2-}$ reduction (indicated times correspond to the measurement start at $610 \mathrm{~nm}$; scan time $=25.3 \mathrm{~s}$ ). B) Time dependence of the $\mathrm{Fe}^{2+} /$ heme concentration, determined from its Q-band (see also Figure S7). C) Time dependence of the chromate concentration, measured at $360 \mathrm{~nm}$.

potentials induced by $\mathrm{Cr}^{3+}$ ions attached to amino acids of Omc.

A much more pronounced increase of the $\mathrm{Fe}^{2+} /$ heme concentration was observed when solid $\mathrm{AgCl}$ nanocrystals served as the oxidant. ${ }^{[3 \mathrm{a}]} \mathrm{AgCl}$ nanocrystals were generated by addition of $\mathrm{AgNO}_{3}$ to a $\mathrm{Cl}^{-}$-containing growth medium (Figure S10), ${ }^{[20]}$ to which the same volume of a bacteria suspension was injected, leading to a $0.1 \mathrm{~mm} \mathrm{AgCl}$ and $0.45 \mathrm{pm}$ G. sulfurreducens solution. Within 5 minutes (Figure $5 \mathrm{~A}, \mathrm{C}$ ) the microorganisms reduced the insoluble $\mathrm{AgCl}$ nanocrystals (Figure 5D) into insoluble AgNPs (Figure $5 \mathrm{E}) .{ }^{[21]}$ The AgNP formation rate remained constant, demonstrating that the product formation again followed a zero order kinetics. However, in sharp contrast to experiments with soluble $\mathrm{Ag}^{+}$ions (Figure $3 \mathrm{~B}$ ), the reduction of solid $\mathrm{AgCl}$ was accompanied by an increase of the $\mathrm{Fe}^{2+} /$ heme concentration from 15 to $95 \%$ (Figure 5B). This implies different reaction mechanisms. With soluble $\mathrm{Ag}^{+}$ions as the oxidant, complexation by Omc proteins led to a certain number of AgNPs at the microorganisms. These are the reaction sites to which the large excess of $\mathrm{Ag}^{+}$ions diffused and became reduced.

The situation with insoluble $\mathrm{AgCl}$ nanocrystals as oxidants was completely different as nearly all $\mathrm{Ag}^{+}$ions were stored in the solid $\mathrm{AgCl}$ nanocrystals. ${ }^{[22]}$ The reduction of each $\mathrm{AgCl}$ particle to an AgNP therefore decreased the concentration of the redox sites, thus the electron flux rate should decrease continuously. However, Figure 5C shows that the rate of the AgNP growth remained constant. This was actually accomplished by the concentration increase of the reaction
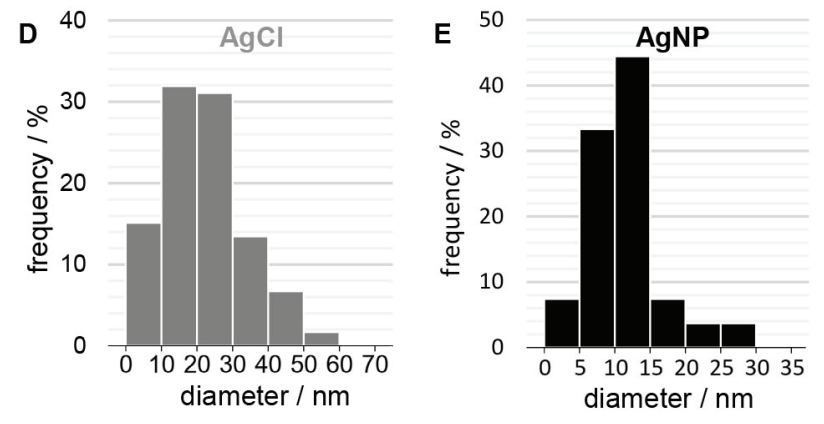

Figure 5. Mineral respiration of $G$. sulfurreducens $(0.45 \mathrm{pm})$ using solid silver chloride nanocrystals $(0.1 \mathrm{~mm})$ as an extracellular oxidant. A) UV/Vis monitoring of the bacterial suspension upon $\mathrm{AgCl}$ reduction (indicated times correspond to the measurement start at $610 \mathrm{~nm}$; scan time $=25.3 \mathrm{~s}$ ) B) Increase of the $\mathrm{Fe}^{2+} /$ heme concentration during the reaction, determined from the Q-bands. C) Linear increase of the scattering at $610 \mathrm{~nm}$ demonstrating zero order kinetics for AgNP formation. D) Size distribution of the oxidizing $\mathrm{AgCl}$ nanocrystals. E) Size distribution of the generated AgNPs.

partners, the $\mathrm{Fe}^{2+}$ /hemes (Figure 5B). Obviously, the increasing $\mathrm{Fe}^{2+} /$ heme: $\mathrm{Fe}^{3+} /$ heme ratio in a multiheme Omc raised its reactivity to such an extent that the AgNP formation rates remained constant. We measured an average ET rate at $30^{\circ} \mathrm{C}$ of $7.5 \times 10^{5} \mathrm{es}^{-1}$ per bacterium with a variation of $\pm 40 \%$ (Table 1). The chemical rates in Table 1 show that respiration of $G$. sulfurreducens using different oxidants occurs with EET rates of $5 \times 10^{5}\left( \pm 2 \times 10^{5}\right) \mathrm{es}^{-1}$ per bacterium at $30^{\circ} \mathrm{C}$. This corresponds to a current production of $80( \pm 30) \mathrm{fA}$, which is similar to electrochemical data. Jian et al. have measured a current of $90( \pm 30) \mathrm{fA}$ in experiments where a single G. sulfurreducens cell was in contact with a gold electrode, ${ }^{[23]}$ and El-Naggar et al. determined currents of $60( \pm 40) \mathrm{fA}$ in electrochemical measurements with Shewanella oneidensis. ${ }^{[24]}$

Our experimental results show that in mineral respiration of $G$. sulfurreducens, the electron flux remains constant during the decrease of the oxidant concentration, demonstrating zero order reaction kinetics. In addition, the electron 
flux rates are nearly independent of the type of the oxidant. This could be a general effect during mineral respiration of anaerobic bacteria; it might occur also with other members of the Geobacter genus or with $S$. oneidensis microorganisms. The independence from the environmental conditions demonstrates the flexibility of these bacteria, which adapt to changing external redox potentials by changing $\mathrm{Fe}^{2+} /$ heme: $\mathrm{Fe}^{3+} /$ heme ratios in the $c$-type cytochromes. Decreasing the reactivity or the number of the reaction sites of the oxidizing metal ions is compensated by an increase of the $\mathrm{Fe}^{2+} /$ heme population in the multiheme outer membrane cytochromes. A constant ET is needed to maintain constant ATP synthesis during respiration. ${ }^{[25]}$ Such ATP homeostasis is a vital condition for living systems. ${ }^{[26]}$ Obviously, the $\mathrm{Fe}^{3+}$ / heme concentrations in the inner membrane cytochromes remain high enough to stabilize the enzymatic respiration reaction. This might be one of the reasons for the high concentration of iron/hemes in these microorgnisms $\left(10^{7}\right.$ per G. sulfurreducens). Thus, ATP homeostasis is the result of an interplay between chemical redox reactions at the outer cell membrane and enzymatic redox reactions at the inner cell membrane (Figure 1B and Scheme 1). The iron/hemes of $c$ type cytochromes, which are the carriers of the electrons, act as buffers that synchronize the ET rates of the electron influx and the electron outflux. This makes G. sulfurreducens a predictable reaction tool for redox reactions.

\section{Acknowledgements}

We thank the Swiss National Science Foundation (Grant Nos. 200020_172777 for V.C. and 200021_178827 for M.K. and L.B., postdoc stipend No. 178650 for M.F. and the NCCR Bioinspired Materials), the Swiss Confederation for an Excellence Grant for E.M., the Fribourg Center for Nanomaterials, and the University of Fribourg for generous support. This research was also supported by the Fundação para a Ciência e a Tecnologia (FCT-MCTES) (grant PTDC/ BIA-BQM/31981/2017 to C.A.S. and UID/Multi/04378/2019 (Applied Molecular Biosciences Unit-UCIBIO)). We thank Peter Schurtenberger/Lund and Stefan Salentinig/Fribourg for valuable discussions.

\section{Conflict of interest}

The authors declare no conflict of interest.

Keywords: electron transfer - Geobacter sulfurreducens . iron heme $\cdot$ silver nanoparticles $\cdot$ silver proteins

[1] For a recent review see: L. Shi, H. Dong, G. Reguera, H. Beyenal, A. Liu, H.-Q. Yu, J. K. Fredrickson, Nat. Rev. Microbiol. 2016, 14, 651-662.

[2] a) D. R. Lovley, J. F. Stolz, G. L. Nord, E. J. P. Phillips, Nature 1987, 330, 252 - 254; b) F. Caccavo, D. J. Lonergan, D. R. Lovley,
M. Davis, J. F. Stolz, M. J. McInemy, Appl. Environ. Microbiol. 1994, 60, 3752-3759.

[3] a) N. Law, S. Ansari, F. R. Livens, J. R. Renshaw, J. R. Lloyd, Appl. Environ. Microbiol. 2008, 74, 7090-7093; b) J. R. Lloyd, J. M. Byrne, V. S. Coker, Curr. Opin. Biotechnol. 2011, 22, 509515 .

[4] "Geobacter: The Microbe Electrics Physiology, Ecology, and Practical Applications": D. R. Lovley, T. Ueki, T. Zhang, N. S. Malvanker, P. M. Shrestha, K. A. Flanagan, M. Aklujkar, J. E. Butler, L. Giloteaux, A.-E. Rotaru, D. E. Holmes, A. E. Franks, R. Orellana, C. Risso, K. P. Nevin, in Advances in Microbial Physiology (Ed.: R. K. Poole), Academic Press, San Diego, 2011, pp. $1-100$.

[5] For a recent review see: A. J. Slate, K. A. Whitehead, D. A. C. Brownson, C. E. Banks, Renewable Sustainable Energy Rev. 2019, 101, 60-81.

[6] a) G. Reguera, K. D. McCarthy, T. Mehta, J. S. Nicoll, M. T. Tuominen, D. R. Lovley, Nature 2005, 435, 1098-1101; b) S. E. Childers, S. Ciufo, Nature 2002, 416, 767-769.

[7] The composition of bacterial filaments (pili) is in some cases still a matter of discussion: a) F. Wang, Y. Gu, J. P. O'Brien, S. M. Yi, S. E. Yalcin, V. Srikanth, S. Shen, D. Vu, N. L. Ing, A. L. Hochbaum, E. H. Engelmann, N. S. Malvanker, Cell 2019, 177, $361-369$; b) D. L. Lovley, D. Walker, Front. Microbiol. 2019, 10 , 2078.

[8] a) J. M. Dantas, M. Silva e Sousa, C. A. Salgueiro, M. Bruix, Biomol. NMR Assignments 2015, 9, 365-368; b) J. M. Dantas, M. A. Silva, D. Pantoja-Uceda, D. L. Turner, M. Bruix, C. A. Salgueiro, Biochim. Biophys. Acta Bioenerg. 2017, 1858, $733-$ 741.

[9] V. Chabert, M. Hologne, O. Sénèque, O. Walker, K. M. Fromm, Chem. Commun. 2018, 54, 10419-10422.

[10] R. Czoik, A. Heintz, E. John, W. Marczak, Acta Phys. Pol. A 2008, 114, A51-A56.

[11] a) J. Hirst, S. K. Wilcox, J. Ai, P. Moënne-Loccoz, T. M. Loehr, D. B. Goodin, Biochemistry 2001，40，1274-1283; b) D. E. McRee, G. M. Jensen, M. M. Fitzgerald, H. A. Siegel, D. B. Goodin, Proc. Natl. Acad. Sci. USA 1994, 91, 12847-11285.

[12] V. Chabert, M. Hologne, O. Sénèque, A. Crochet, O. Walker, K. M. Fromm, Chem. Commun. 2017, 53, 6105-6108.

[13] a) UniProtKB-Q749K5(CYCB_GEOSL); b) UniProtKBQ749L1 (CYTC_GEOSL).

[14] In a study using different $\mathrm{AgNO}_{3}$ amounts these concentrations turned out to be appropriate for detailed experiments. The preparation of the G. sulfurreducens solution followed the procedure described in S. I. Vasylevskyi, S. Kracht, P. Corcosa, K. M. Fromm, B. Giese, M. Füegg, Angew. Chem. Int. Ed. 2017, 56, 5926-5930; Angew. Chem. 2017, 129, 6020-6024. The growth medium is given in Figure S5. The experiments were carried out under strictly anaerobic conditions. The $\mathrm{OD}_{600}$ values for different $G$. sulfurreducens generations varied between 0.45 and 0.75 . Dilution experiments showed that $\mathrm{OD}_{600}$ changed in a linear way. The kinetic experiments were carried out in $3.0 \mathrm{~mL}$ of thermostatted G. sulfurreducens suspensions to which $0.1 \mathrm{~mL}$ $\mathrm{AgNO}_{3}$ solutions were added with a syringe, so that the concentration in the reaction mixture was $0.05 \mathrm{~mm}$. The concentrations of the $\mathrm{Cl}^{-}$and $\mathrm{Fe}^{2+}$ ions in the solutions were 2 and about $10 \mu \mathrm{M}$, respectively. The $\mathrm{Fe}^{2+} /$ heme concentrations were determined by integration of the Q-band areas.

[15] We detected that the intensity at $610 \mathrm{~nm}$ increased linearly in experiments with increasing $\mathrm{Ag}^{+}$concentration. We checked the $\mathrm{Ag}^{+}$concentrations in the mother liquor by ICP spectroscopy: when the intensity increase had stopped, $\mathrm{Ag}^{+}$ions in the mother liquor could no longer be detected, and the analysis during the redox reaction showed a decrease in the $\mathrm{Ag}^{+}$concentration. Thus, we concluded that this intensity change might be an acceptable way to measure the formation of AgNPs. We decided 
to use this observable, because ICP experiments were not very precise, as the bacteria had to be removed by filtration or centrifugation. Both procedures took time during which the microbiological reaction continued. In addition, during filtration some $\mathrm{Ag}^{+}$ions might be removed by the bacteria in the filter pores. A further complication was that the redox process were fast, requiring only a few minutes (Figure 3), which caused large errors in the ICP experiments. Therefore, we used the intensity at $610 \mathrm{~nm}$ to measure the formation and growth of AgNPs. In future work we will further study this phenomenon.

[16] Complexation of $\mathrm{Ag}^{+}$ions by $\mathrm{Omc}$ at the beginning of the experiment generated the AgNP growth sites. Analyses of several TEM pictures showed that the number of AgNPs number is always less than $10^{2}$ per microorganism (see, for example, Figure $3 \mathrm{D}$ ). The excess of the $\mathrm{Ag}^{+}$ions per microorganism at the beginning of the experiment was $0.7 \times 10^{8}$.

[17] From the rate coefficient of $0.5 \times 10^{10} \mathrm{~L} \mathrm{~mol}^{-1} \mathrm{~s}^{-1}$ for the addition of $\mathrm{Ag}^{+}$ions to neutral $\mathrm{Ag}^{0}$ one can assume that also the reaction with AgNPs might be very fast, see: A. Henglein, Chem. Rev. 1989, 89, 1861-1873; A. Henglein, Ber. Bunsen-Ges. 1977, 81, $556-561$. ET reactions through the multiheme cytochrome MtrF of Shewanella oneidensis had been calculated to be about $10^{4} \mathrm{~s}^{-1}$ : M. Breuer, K. M. Rosso, J. Blumberger, Proc. Natl. Acad. Sci. USA 2014, 111, 611-616. ET between the iron/hemes of different cytochromes should be even slower.

[18] The number of iron/hemes had been determined to be about $10^{7}$ per Geobacter sulfurreducens: A. Esteve-Núñez, J. Sosnik, P. Visconti, D. R. Lovley, Environ. Microbiol. 2008, 10, 497-505.

[19] The kinetic experiments were carried out as described for $\mathrm{AgNO}_{3}$ reactions. Under strictly anaerobic conditions, $0.1 \mathrm{~mL}$
$\mathrm{Na}_{2} \mathrm{CrO}_{4}$ solutions were added to the bacterial suspension in such concentrations that the chromate concentrations were 0.05 or $0.1 \mathrm{~mm}$. Variation of the $\mathrm{Cl}^{-}$concentration had no effect on the EET rate.

[20] Under strictly anaerobic conditions, $0.05 \mathrm{~mL}$ of a $0.3 \mathrm{M} \mathrm{KCl}$ solution was combined with $1.35 \mathrm{~mL}$ of the growth medium. Injection of $0.1 \mathrm{~mL}$ of a $3 \mathrm{~mm} \mathrm{AgNO}_{3}$ solution generated $\mathrm{AgCl}$ nanocrystals, as powder X-ray measurements proved (Figure 5D and Figure S9). After a few seconds, the mixture became clear and was combined with $1.5 \mathrm{~mL}$ of a suspension of G. sulfurreducens in the resting state.

[21] Using the dimensions of the $\mathrm{AgCl}$ unit structure, the number $n$ of $\mathrm{Ag}^{+}$ions in roundish $\mathrm{AgCl}$ nanocrystals with a diameter $d$ is $n=$ $12 \cdot d^{3}$. The number of $\mathrm{Ag}^{0}$ in AgNPs is $n=30 \cdot d^{3}$, see: A. Henglein, M. Giersig, J. Phys. Chem. B 1999, 103, 9533-9539.

[22] A medium-sized $(20 \mathrm{~nm}) \mathrm{AgCl}$ nanocrystal contains about $10^{5}$ $\mathrm{Ag}^{+}$ions.

[23] X. Jiang, J. Hu, E. R. Petersen, L.-A. Fitzgerald, C. S. Jackan, A. M. Lieber, B. R. Ringeisen, C. M. Lieber, J. C. Biffinger, Nat. Commun. 2013, 4, 2751.

[24] B. Gross, M. Y. El-Naggar, Rev. Sci. Instrum. 2015, 86, 064301.

[25] M. Saraste, Science 1999, 283, 1488-1493.

[26] H. Y. Kueh, P. Niethammer, T. J. Mitchison, Biophys. J. 2013, $104,1338-1348$. 


\section{Communications}

\section{Electron Transfer}

V. Chabert, L. Babel, M. P. Füeg, M. Karamash, E. S. Madivoli, N. Herault, J. M. Dantas, C. A. Salgueiro, B. Giese,** K. M. Fromm* III-III

Kinetics and Mechanism of Mineral Respiration: How Iron Hemes Synchronize Electron Transfer Rates

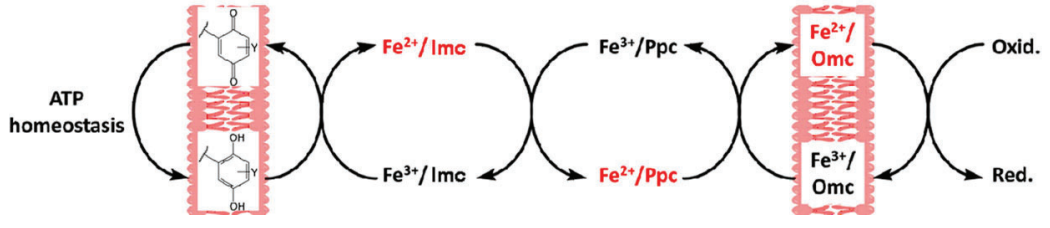

The bacterium Geobacter sulfurreducens requires extracellular metal salts for respiration. Each microorganism produces $5 \times 10^{5}$ electrons per second, which membrane cytochromes. With iron heme cofactors of $c$-type cytochromes, the electron flow is independent of the concentration and type of oxidant. This results in ATP homeostasis. 